\title{
The Determinates Of Selecting Accounting Software: A Proposed Model
}

Ahmad A. Abu-Musa, (Email: abumusa@kfupm.edu.sa), King Fahd University of Petroleum \& Minerals, Saudi Arabia

\begin{abstract}
Selecting the appropriate accounting software has become an important issue for many organizations. Selecting the wrong accounting software would be a great disaster, it might lead to major financial losses, and possibly even bankruptcy. Certain crucial factors such as users' current and future needs, business type, business size, features and attributes of accounting software, information technology infrastructure and environment, and vendor reliability should be taken into consideration before obtaining the software. The objective of this paper is to investigate, analyze and evaluate the main factors an organization should consider in its decision to select the appropriate accounting software. The paper introduces an integrated theoretical framework of the main factors affecting the selection of an appropriate accounting software package for an organization. The paper proceeds to introduce a proposed mathematical model of the determinants of selecting accounting software. The proposed model would help an organization to select the most appropriate accounting software that would satisfy its current and future needs for information and financial and non-financial reports.
\end{abstract}

\section{A. INTRODUCTION AND THE NATURE OF THE PROBLEM}

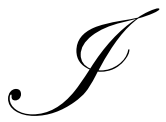

$\mathrm{t}$ is argued that we have come a long way from "paper and pencil" accounting systems. Accounting software packages have become commonplace for many organizations in recording business transactions, preparing financial statements and analyzing operations. Accounting software has freed accountants from the manual recording and presentation of financial data. By using accounting software, financial transactions would be recorded more quickly and accurately at a relatively low cost. Moreover, accounting software packages increased overall operational effectiveness by improving both the quantity and quality of management information available (Collins, 1999; Fisher and Fisher, 2001; and Abu-Musa, 2004).

Years ago, when personal computers were just coming into their own, accounting software was relatively simple. Its single function was to automate the task of double-entry accounting and produce a straightforward balance sheet. As computers became more robust and integrated databases standardized, accounting software developers added more functions-including cost accounting, manufacturing resource planning, customer resource management, human resources, and payroll (Jones, 2002).

Henry (1997) confirmed that the steady decline in the price of information technology and the increasing availability of "off the shelf" accounting software have led more and more businesses of any size to automate all or part of their accounting functions. Further, in an effort to be extremely "user friendly", accounting software requires little knowledge of accounting to be put to effective use.

User-friendly accounting software might also create significant risks related to the security and integrity of computer and communication systems, data, and management information. West and Zoladz (1993) stated that "although computers provide many benefits, inherent computer security issues are not often addressed by management. Many organizations do not realize the importance of computer security until some unauthorized modification to a payroll file, or some other events, occur. Because information might be an organization's most valuable asset, leaving it without protection is tantamount to underinsuring fixed assets or inventory". Accordingly, in 
selecting accounting software package, organizations can no longer afford to ignore the importance of information security in the light of computer fraud, hackers, computer viruses, and other security threats (Abu-Musa, 2004).

Jones (2002) argued that in selecting accounting software and the attributes one wants in that accounting software resembles in many ways those one is likely to seek when choosing a spouse. One wants a faithful (accurate) helpmate who grows with him / her (capable of being scaled up). One wants someone he/she can treasure through sickness (financial loss) and in health (profitable growth). One wants the candidate to be capable of intimacy (keep confidences) yet be open to recognizing his or her faults (an audit function to find and fix errors). And most important one wants the relationship to be long lasting-without the need for expensive and debilitating upgrades.

Selecting the most appropriate accounting software package has become one of the most critical decisions for most organizations in the fast-changing business world. Therefore, the accounting software package an organization chooses should be the one that best serves its current needs and can most easily be adapted to satisfy its future needs for information and financial and non-financial reports. Selecting the right accounting software package cannot be taken lightly. If the wrong accounting software is selected the company would be faced with spending a great deal of time and money to acquire and implement a new one. Selecting the wrong accounting software would be a complete disaster for an organization, it might lead to great financial losses, and possibly even bankruptcy. Therefore, it is recommended that an organization should spend a considerable time researching all aspects of the accounting software before taking a decision of buying it. It is argued that purchasing an accounting software package could be the most important company purchase during its life, and should be treated as one of the most important strategic decisions. (See: Simkin, 1992; Tavakolian, 1995; West and Shields, 1998; Tate, 1999; Soukup, 2000, Mattingly, 2001; Basile et al. 2002; Deshmukh and Romine, 2002; Sampson, 2003; and Abu-Musa, 2004).

Mattingly (2001) stated that choosing the right accounting software is becoming more difficult as the software market becomes increasingly fragmented. In many cases, more product information makes decision-making more difficult rather than less. The risks of leaping into an expensive purchase decision are hard to assess. Collins (1999) also confirmed that selecting the appropriate accounting software for an organization requires a close investigation of many diverse areas. It has been observed that, in selecting accounting software many organizations emphasize on satisfying their current and short term needs for information and financial and non-financial reports, rather than their future and long term needs. According to Collins (1999) an organization's long-term needs is an area that often gets lost in the technical assessments of accounting software. It is critical that one should evaluate an organization's requirements beyond the immediate and short term needs. It is also argued that businesses grow and so do their accounting software needs. Accordingly, Collins (1999) advised that an organization should assess the way that its employees use the applications and their needs should be considered in the purchasing decision. However, this does not imply that needs of everyone should be given equal weight. For example, bookkeepers and data-entry staff might tend to place more emphasis on the data-entry task of getting cash and inventory in and out the door, while accountants would focus on providing management with the necessary financial and non-financial reports. It is argued that those making buying decisions rely heavily on the bookkeepers' and data-entry clerks' assessments of needs and give short shrift to the product's reporting capabilities.

Acquiring the most appropriate accounting software would not be an easy task. One would face many challenges to get accurate and valid information that might be needed to evaluate the competent accounting software packages, and to take the right selection decision. Trade shows, seminars, and magazine articles related to selecting accounting software are typically just telling one about the good stuff. The vendors at trade shows usually provide the users with fancy brochures in which they show the competitive advantages and capabilities of their products. Vendors often skim over or hide the weaknesses or missing bits in their accounting software. They usually try to convince the customer that their product will do all what he/she wants, whether this is actually the case or not. It is less likely or almost impossible that venders would inform the customer about what is missing or what is wrong with their product (Collins, 1999; Tate, 1999; and Abu-Musa, 2004).

The lack of reliable independent source of information makes selecting the appropriate accounting software for an organization more complicated. Moreover, many organizations - especially new established ones- might not have comprehensive and well-developed lists of their current and future needs for accounting software, which make 
selecting appropriate accounting software a very difficult task. An organization transferring from manual to computerized accounting systems might lack clear guidelines regarding the main criteria that should be considered in selecting appropriate accounting software, such an organization might have low expectations regarding the capabilities of accounting software, believing that using accounting software would result only in just recording and processing financial transactions much faster and more accurate. On the other hand, organizations that are facing some problems and shortcomings related to their computerized accounting system in place would expect the new software to solve their current problems - overlooking future needs. Accordingly, business strategies and future plans might not be considerably taken into account in such a strategic decision.

Reviewing the available literature revealed that there were neither an integrated comprehensive theoretical framework nor a mathematical model of the main factors and determinants that should be considered in selecting the appropriate accounting software for an organization. The arbitrary selection of accounting software would be a real disaster. Many organizations still believe that no one can guarantee that the selected software would match its current and futures needs for information until the accounting software is completely installed and successfully running. However, it might take a month or few months of operations to investigate whether the selected accounting software satisfies an organization's needs, and by then it would be too late to change it.

The remainder of this paper is organized as follows. The next section highlights the research objectives while section three presents the research methodology. The theoretical framework of the determinants of selecting accounting software and its main components will be discussed in section four. Section five introduces the proposed model of the determinants of selecting the most appropriate accounting software for an organization. This is followed by stating the main steps and procedures of implanting the proposed model in section six, while section seven presents the limitation of the proposed model. The final section of the paper provides the conclusion and recommendations for further research.

\section{B. THE RESEARCH OBJECTIVES}

The main objective of this paper is to investigate, analyze and evaluate the main factors an organization should consider when selecting accounting software. The paper aims also to develop an integrated theoretical framework for the main determinants that would guide and help an organization in selecting the appropriate accounting software that suits its current and future needs. The paper also introduces a proposed mathematical model for the determinants of selecting accounting software for an organization, and presents the empirical steps and procedures to implement the proposed model and put it into practice. The theoretical framework and the proposed model would be beneficial for new organizations considering acquisition of accounting software for the first time and those organizations transferring from manual to computerized accounting systems. It would help organizations in evaluating competitive accounting software packages and rationalizing the selection decisions.

\section{THE RESEARCH METHODOLOGY}

The analytical approach is used in this paper to study, analyze and evaluate the main factors that should be considered in selecting the most appropriate accounting software for an organization. The paper introduces an integrated theoretical framework which links and matches the main characteristics and features of accounting software with business type and size, and the current and expected customer's needs related information and financial and nonfinancial reports. The deductive approach is also used to develop a proposed mathematical model of the determinants of selecting accounting software based on studying, analyzing, and evaluating the proposed determinants in the theoretical part of the paper. Delphi technique was implemented in calculating the maximum points assigned to each determinant in the proposed model according to its materiality using a selected research sample. The proposed model is flexible, the maximum points assigned to each determinant could vary from one organization to another according to their materiality and relative importance to that organization. The proposed accounting software evaluation form (Appendix 1) is expected to help organizations in this regard. The next section will discuss the main determinants of selecting the most appropriate accounting software for an organization and an integrated theoretical framework will be presented. 


\section{DETERMINATES OF SELECTING AN APPROPRIATE ACCOUNTING SOFTWARE: A THEORETICAL FRAMEWORK}

The objective of selecting appropriate accounting software is to match the product's features with the user's needs. Collins (1999) argued that the single most important question is whether the accounting software could be customized - and if it could, whether the amount of customization is capable of meeting an organization's requirements. Vendor reliability would be also critical. No matter how good a product is, users still have to rely on the vendor. It is usually advised to avoid vendors with limited resources. Since a primary objective of any financial accounting system is producing accurate and reliable financial statements on a timely basis, one should be sure that the accounting software being considered would produce the kind of financial reports that are required - and that it included a wide variety of financial and business reporting ratios.

The process of selecting the accounting software package that best fits an organization's needs might be difficult. Some general steps to follow in evaluating and selecting alternatives are:

- $\quad$ Develop macro-level criteria;

- Do an initial screening of packages to arrive at a short list;

- $\quad$ Define detailed requirements for specific functions of every management area you expect to computerize;

- $\quad$ Evaluate the short list through the request for proposal (RFP) process, vendor demonstrations, and vendor site visits;

- $\quad$ Perform cost/benefit analyses;

- $\quad$ Call and/or visit vendor references;

- $\quad$ Select the alternative that seems to provide the best fit;

- $\quad$ Plan for design and implementation of the package;

- Develop detailed cost estimates, business case, and value propositions for the project;

- $\quad$ Conduct software contract negotiations; and

- $\quad$ Arrange for implementation assistance (i.e., internal or consultants) (Morey, 1999).

Morey (1999) also mentioned that organizations are using technology to provide themselves with increasing efficiencies and competitive advantages in the marketplace. Used strategically, technology can be the differentiating factor that separates a company from the competition and provides new opportunities for growth. The overriding consideration is finding software compatible with a company's long-term business goals and the needs of tenants and clients. However, caution must be exercised to keep the planning, implementation, and use of information systems focused on supporting business strategies, organizational structure, and operational requirements-not an end unto itself.

According to Gurton (2001), power and ease of use are no longer the only criteria for selecting an accounting system. Ease of use is still important but compatibility has increased in importance, too. Now that companies need to communicate via the Internet or Intranet, all must conform to the same standards of transmission and file structures. Despite claims of compatibility, however, it is frequently lacking at the level necessary. The new web-based technology does not only mean universal connectivity, but also inter-operability throughout the enterprise and the embracing of new business techniques like customer relations management. The accountant needs to take a holistic view of the business's needs to ensure that all requirements, now and in the future, will be met.

Collins (1999) argued that there is an old saying, if you ask the wrong question; you are likely to get the wrong answer. That certainly applies when accountants ask which accounting software product is the best. The fact is, there is no best accounting software. There is no single product that suits everyone's needs; but there are probably several that suit one company's specific requirements. So, since the problem is matching software products with a user, the correct question is: how should I go about finding the packages that are right for my business or client? When it comes to accounting software, the search begins by examining both the products' features and the vendors behind the products. Collins (1999) also stated that "because accounting software contains hundreds-if not thousandsof features, this may seem like an overwhelming task. While such assessments are not exactly easy, they are not 
overly difficult, because only a handful of features are critical to making the right choice-and one should focus on those features".

During the selection process, it is important to document each accounting software package, its features, its pros and cons, and whether it fits an organization's needs. This information will make it easier to narrow down the choices by developing a short list of promising accounting software. The current and future end users' requirements, the nature of business and its size, IT environment and infrastructure, the accounting software features and the vendors' capabilities of the accounting software packages should be assessed and considered in order to select appropriate software package for an organization (Figure 1). The main factors that should be considered in selecting accounting software packages will discussed in the following sections

\section{1. END USER REQUIREMENTS}

One of the biggest technology issues facing start-up and smaller companies is choosing the most effective accounting software. Small businesses must remember that the right accounting package is the one that best services the current needs of the business and that can be most easily adapted to their future needs. However, the right solution goes beyond just accounting software, customers' support is also important, especially at the outset (Basile et al., 2002). Therefore, it is helpful to think of the software selection decision as a two-fold process: the first step is to decide which features are most important; in the second step, one selects the software that best matches these needs (Simkin, 1992).

Acquiring appropriate accounting software for an organization could be a real challenge, and should not be undertaken without serious forethought. Certain crucial factors should be taken into consideration before obtaining the accounting software package. One should assess the business' requirements for information and financial and nonfinancial reports before investing in any accounting software package. The main features and attributes of the selected accounting software package should be able to satisfy the business current and future needs. The main factors affecting the end users' current and future requirements of accounting software package will be discussed in the following sections.

\section{Current Needs}

The company must ascertain the problems with the current system. Before deciding that new software is needed, make sure that the most current version is running on the right system. Pinpointing the problems with the current system will help determine what the company should look for in a new package. All employees should have an opportunity to explain their problems with the current system and their expectation of the new system. Once the analysis is complete, the company should eliminate software packages that clearly do not fulfill their needs. This entails evaluating what each program has to offer against what the company requires from their accounting software (Basile et al., 2002).

In many cases implemented accounting systems in an organization do not adequately satisfy its needs. The first step in that case is to define the problems related to accounting systems in place. A comprehensive list of shortcomings, weaknesses of the accounting software in use should be determined. However, in order to identify the current problems and issues, it might be helpful to survey the opinions of all end users of the accounting software and to ask for their feedback on a regular basis. Preparing the "Needs Analysis Document" would help in formalizing this process by writing an organization's current and future needs in a precise way. 


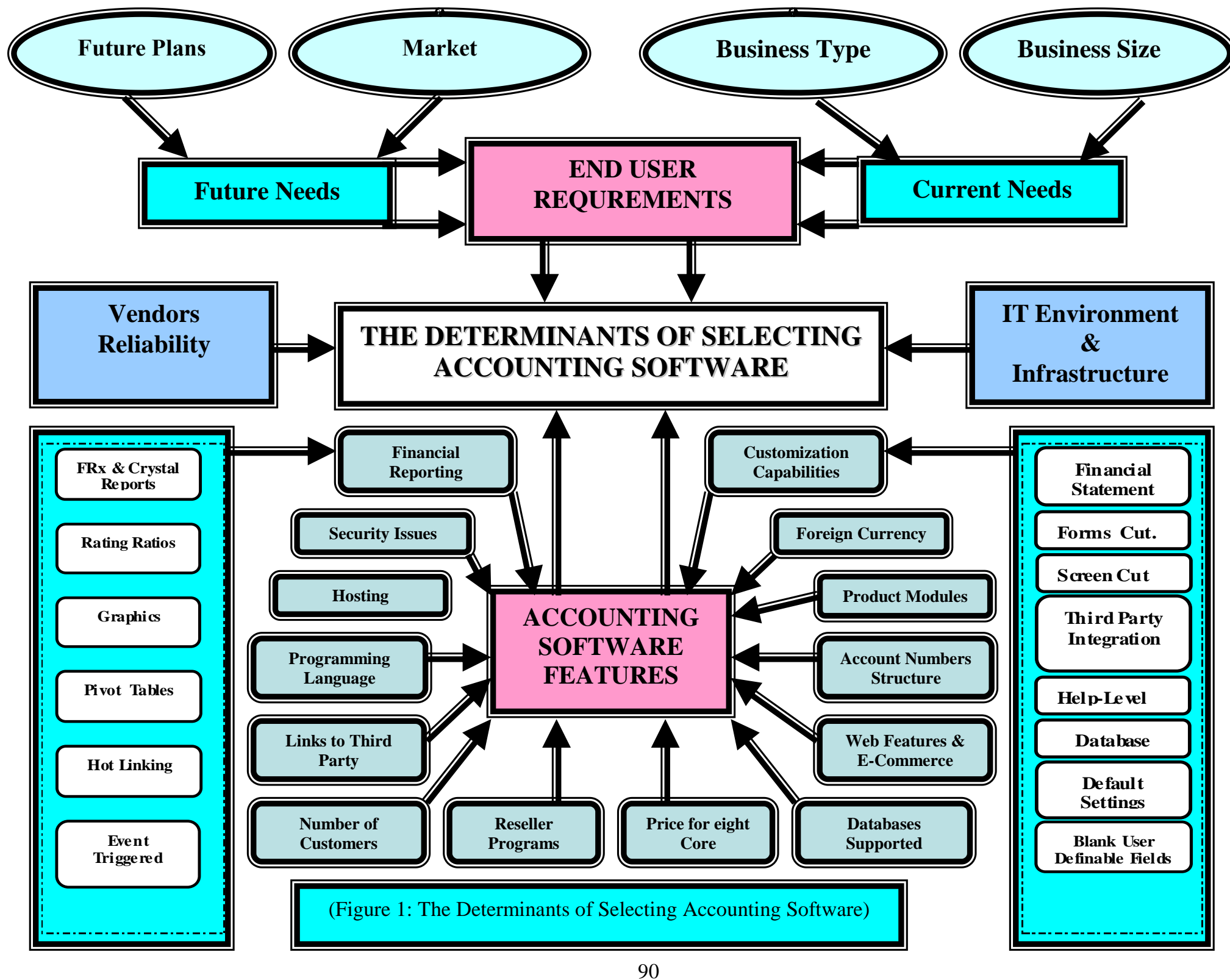


Simkin (1992) stated that the accounting software features required by end users are usually dictated by the nature of their organization and can generally be determined by analyzing their existing accounting systems. For example, if an organization sells both products and services, it would require software that can bill for both products and services. Similarly, if an organization requires departmentalized accounting, it must have software that supports this function. Simkin (1992) cautioned that one should not have to trust someone else regarding the vital features he / she required in the accounting software. For example, if the user must have network capability or departmentalized

The selected accounting software package should help the user to manage the business better by tracking receivables, managing cash flow, controlling inventory and, in addition it should convey the user's financial position and empower them to make important decisions based on objective information. Accounting software should also support report generation, e-commerce, electronic fund transfer, tax requirements, multiple exchange rates and conversion methods, and the ability to translate into other languages (Soukup, 2000; Mattingly, 2001; Deshmukh and Romine, 2002; and Abu-Musa, 2004).

\section{Business Size}

An organization should decide the expected number of individuals who might use the accounting software simultaneously. It is observed that almost all the top accounting software publishers provide retail pricing for the cost of the eight core modules (general ledger, accounts receivable, accounts payable, payroll, inventory, order entry, job costing, and system management) for 1 user, 5 users, 10 users, 25 users, and 100 users. An organization should select the appropriate accounting software package according to the expected number of users who might use the accounting software at the same time. According to Mattingly (2001), "businesses that anticipate increasing numbers of transactions, or many additional users, will want a scalable database to handle their growth. This may considerably increase the software's cost and significantly affect the usual variables of implementation and support".

\section{Business Type}

Accounting software packages might be classified as: (a) general accounting software, and (b) specialized accounting software. Specialized accounting software are designed especially to fit the requirements and special needs of some users such as Government Accounting, Fund accounting, Property Management, Oil and Gas, Farming, and General Accounting and Manufacturing software packages. The most popular specialized accounting software packages that have done a good job in specific industries are: Blackbaud (Donor Software), American Fundware (Fund Accounting), Deltek (Government Accounting), Squirrel (Restaurants), Yardi (Property Management), Sun Systems (Oil and Gas), Cougar Mountain (low-end to mid range), Red Wing (farming and general accounting), CYMA (general accounting for the mid range), and Made2Manage (Manufacturing).

\section{Future Needs}

West and Shields (1998) stated that selecting accounting software should be considered as a strategic decision. Strategic selection is more about selecting a strategic business partner than it is about finding the one best package. It is more about having flexibility to meet future needs than it is about meeting specific current needs. The goal is to get top management's commitment to technology that enables change in the organization, not merely to select and put in a new software package. Therefore, selections should address the strategies and issues of the organization at the top levels. These systems should be chosen with the strategic needs of the organization in mind and not be focused on lower-level, detailed functional requirements.

Accordingly, the first step in the process is to analyze the strategic requirements for the new software. An organization's management needs to answer the following questions: What are our business strategies and plans for the next three to five years? What are the business drivers for this organization? Are we planning to grow substantially? Will we grow through acquisitions or through internal activities? Are there any major re-organizations planned? Do we plan to take our products global? What partnerships (with customers and suppliers) and joint ventures are we considering? Who are our major competitors, and what do we expect their moves to be? What are our competitive advantages? What are the things that we must do well to beat the competition? How are we currently 
using technology? What do our current systems look like? Where are the gaps in technology support for the organization? Do they provide the information needed to analyze the business and make decisions? How well are these systems integrated? Are we using new technologies like client/server, EDI, data warehousing, and the Internet? is technology being used by our competitors, customers, and suppliers? What do we know about the technology used by others in our industry? What new applications are being developed? Do our customers and suppliers want EDItransmitted documents or direct access to our system to review inventory levels or order status? (West \& Shields, 1998).

\section{2. ACCOUNTING SOFTWARE FEATURES}

The second main factor that would significantly affect the selection among accounting software packages is the features of the accounting software packages. The main features of accounting software package are: customization capabilities, financial reporting, account numbers structure, Web features and e-commerce, foreign currency, databases supported, product modules, price for eight core modules, reseller programs, number of customers, links to third party, programming language, hosting, and security of accounting software (Figure 2).

\section{Customization Capabilities}

One of the most important features that should be considered in selecting appropriate accounting software package is its ability to be customized to satisfy an organization's particular requirements. Many of the recent accounting software allow the end user of these products to modify them easily. According to Fisher and Fisher (2001) customization capabilities of accounting software is a real concern. Some off-the-shelf applications are offered with very little or no opportunity for customization to meet an organization's needs, while other vendors will work with the end user to tailor the applications to meet their organization's needs. They argued that the greater the opportunity for customization the greater will be the cost of the applications.

Collins (1999) noted that the most important question one needs to resolve before deciding on an accounting software package is whether it could be customized-and, if it could, whether the customization will meet the user requirements. The main customization levels are: financial statement-level customization, forms-level customization, screen-level customization, blank user definable fields, default settings, database-level customization, third party integration customization, and help-level customization (Figure 3). The main customization capabilities of accounting software packages will be briefly discussed in the following sections.

\section{Financial Statement-Level Customization}

Customization of financial statements and reports is the most simplistic and important feature of an accounting software. It presents the ability of the accounting software to create new financial statements or edit existing financial statement formats. Some accounting software also allow the user to change the font, add lines, and even add graphic pictures, such as a company logo, directly to the financial statement. This type of customization is fairly common as most accounting software do offer this level of customization. However, some products offer much easier-to-use tools than others. Therefore, one should evaluate this prospective of products by asking the seller to demonstrate the process of inserting a new column and moving an element on both a report and form (Collins, 1999; Abu-Musa, 2004).

\section{Forms -Level Customization}

According to this feature, the user will be able to customize accounting system forms such as checks, invoices and packing slips. This ability allows the end user to edit the form formats by adding new information to the form or rearranging the information so that it will print properly on pre-printed forms. For example, a user might want to continue using old preprinted checks or invoices even though the organization has just upgraded to a different accounting system. This customization feature allows the user to adjust such printings to fit the old design or to contain exactly the information they desire (Collins, 1999). 


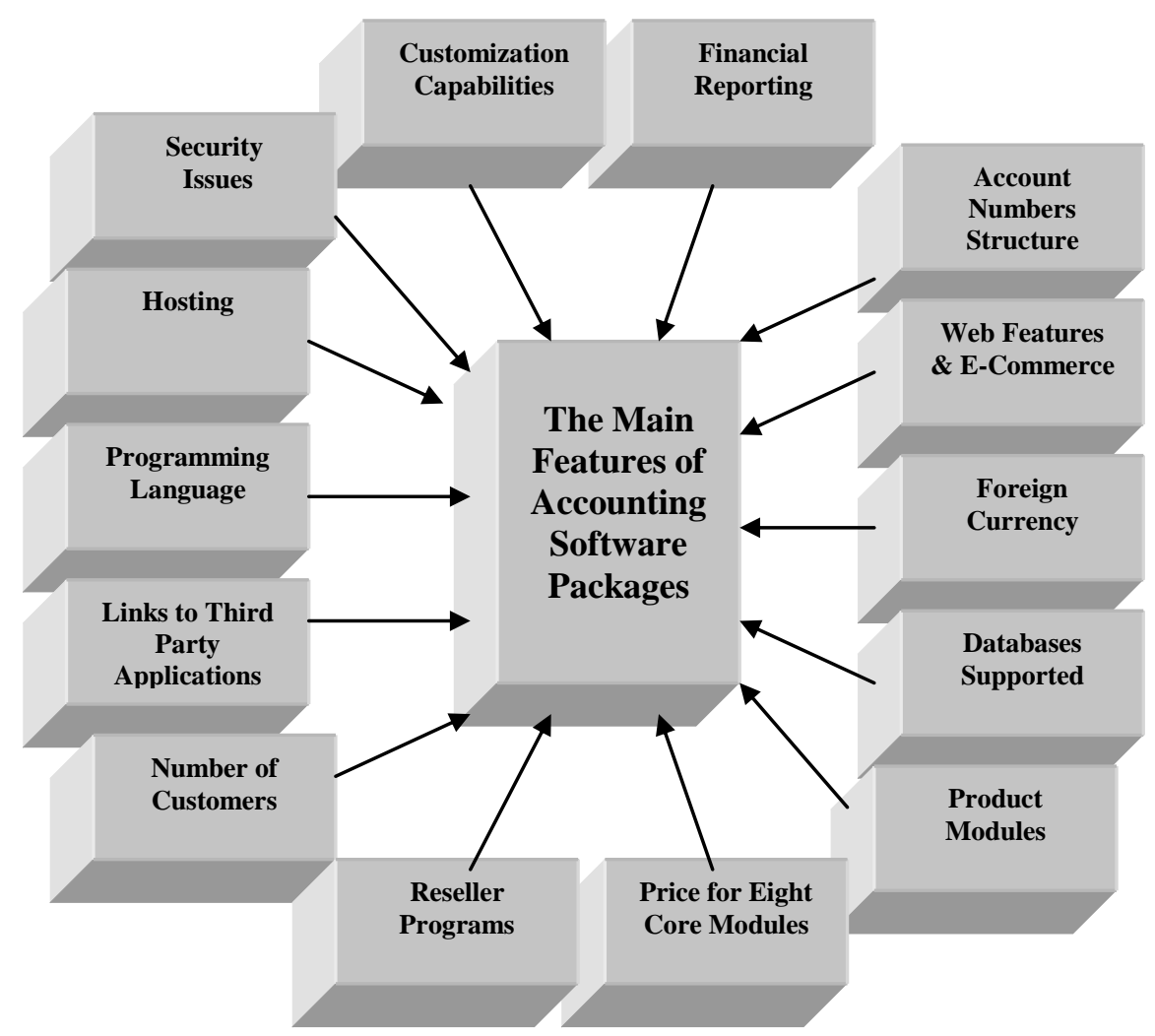

Figure 2: The Main Features of Accounting Software Packages

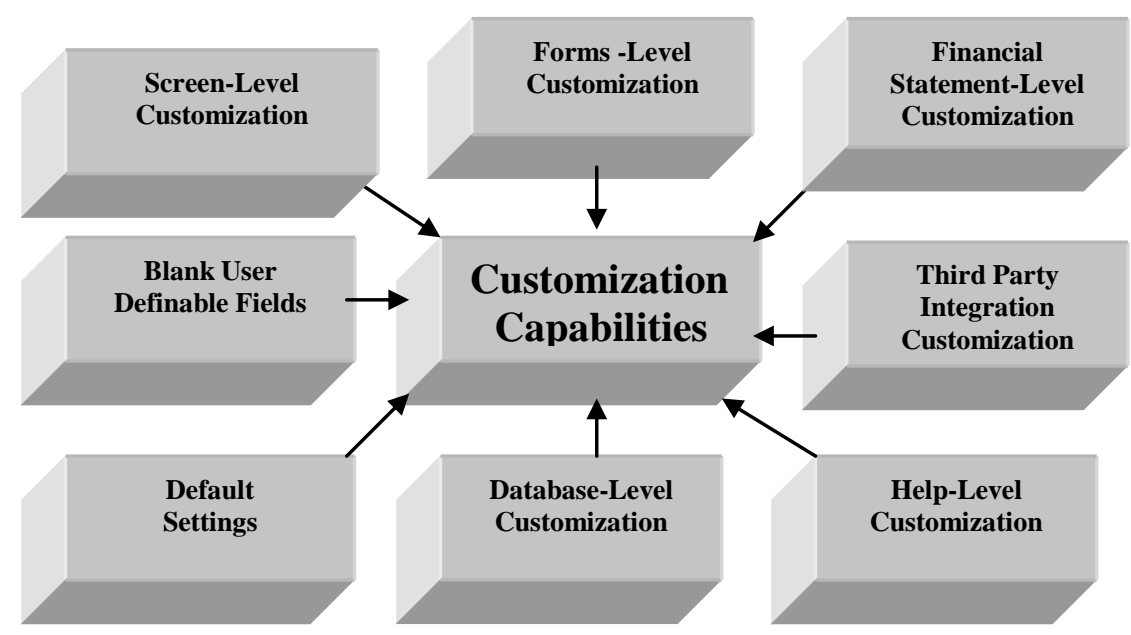

Figure 3: Customization Capabilities of Accounting Software 


\section{Screen - Level Customization}

Screen-level customization allows the user to edit, change and add to the data input screens. Users typically can rename, rearrange and even hide existing fields. One should evaluate this prospective of products by asking the seller to demonstrate the process of changing data labels, rearranging data fields on screen, changing the tab order of the fields, inserting new data fields, setting defaults and inserting new tabs on tabbed dialog boxes. Some products might provide full control over the data input screen design while others do not. Other sophisticated capabilities include the ability to set the tab order of the user fields, insert drop down boxes, and embed third party applications with the accounting software user input screen (Collins, 1999).

\section{Blank User Definable Fields}

One of the most favorite features of accounting software packages is the blank user-definable field. This feature enables the end user of accounting software to add new data using the hundreds of unused fields added throughout the accounting system instead of modifying the source code of the accounting software. The end user on accounting software would need only assign a name to that new field and begin inputting data. Accordingly, in selecting an appropriate accounting software one should ensure that the number of blank user-definable fields included in the accounting software satisfies an organization's current and future requirements and needs.

\section{Default Settings}

Some accounting software products allow the user to specify default settings on a field-by-field basis. Collins (2002) argued that a company that works primarily in Georgia might pre-configure the customer and order entry screen to automatically display Georgia as the default state for each new record. This can save time and improve accuracy. At first glance this might not seem to be much of a time saver, but considering that many organizations process tens of thousands of invoices each year, without a default setting, organization's order entry clerks would need to enter "Georgia" or "GA" tens of thousands of times - once for each order. Most organizations have default terms, shipping methods, categories, sales person codes, currency codes, etc. By simply establishing default data, even modest sized organizations could save hundreds, if not thousands of hours each year in data entry time. As a twist to this feature, some accounting packages allow the user to setup Boolean lists, or drop down lists to improve speed and accuracy. Still other products enable the user to setup automatic calculations, which enter the default data on the fly. For example a product may use the system's date and payment terms to automatically calculate and enter the discount date or due date.

\section{Database - Level Customization}

Database customization allows the end users to change, edit, or add fields and tables to the database of the accounting software. The database customization feature makes database more flexible to satisfy particular requirements of the business and to handle its transactions without changing the database source code. The availability of such feature increases accounting software efficiencies by making it more powerful and friendly to use which would increase its reputation and competitive advantages in the marketplace.

\section{Third Party Integration Customization}

Another aspect of customization capabilities that one should consider in selecting accounting software is its ability to integrate third party products with the financial applications. Some accounting software could be much better than others at achieving this feature. However, most popular accounting software in the marketplace has an import feature that allows end users to import data files from other applications such as Microsoft Excel or Microsoft Access. The existence of such a feature in an accounting software could save time by eliminating duplication of effort. 


\section{Help - Level Customization}

Some accounting software packages offer the end user the ability to enter additional text directly into the help screens. The existence of such feature could increase the usefulness of accounting software and enhance its adaptation ability if it is properly done. This feature makes an accounting software package more sensitive for organizational, economical, cultural, and environmental needs of an organization.

\section{Financial Reporting}

A primary objective of any financial accounting system is to provide accurate financial statements on a timely basis. Organizations frequently complain that their accounting software do not produce required financial reports. Other organizations may not be considering the importance of financial reporting, and therefore they fail to fully consider financial reporting capabilities when evaluating and selecting accounting software packages (Collins, 1999; Sampson, 2003; and Abu-Musa, 2004).

The most important aspects of financial reporting are the built-in FRx and Crystal Reports, Rating Ratios, Graphics, Pivot Tables, Hot-linking, and Event Triggered Reporting (Alarms) (Figure4). The main elements of the financial reporting characteristics and attributes will be briefly discussed in the following sections.

\section{FRx And Crystal Reports}

When it comes to financial reporting, many accounting software products incorporate two third-party products-FRx and Crystal Reports-into their packages rather than develop their own. In recent years those two products have become industry standards. Both work seamlessly with more than 25 top accounting software packages. So dominant is FRx that some products, such as Great Plains Dynamics, Platinum for Windows and Solomon IV, rely on it as their primary financial reporting tool (Collins, 1999).

In evaluating accounting software, an organization should ask whether such accounting software works with FRx or, if it doesn't, whether the built-in module exhibits comparable features. Collins (1999) introduced the following key capabilities and attributes of FRx:

- $\quad$ Produces financial statements with up to 256 columns.

- Links financial data from either a general ledger or other products such as a spreadsheet or database application.

- $\quad$ Creates calculations such as expenses divided by units produced.

- $\quad$ Produces provisional financial statements - that is, as if all un-posted transactions have been posted.

- Views reports on screen and easily drills down from financial summary information into account and transaction details.

- $\quad$ Sends e-mail reports directly to remote users from the report preview screen.

- $\quad$ Exports and imports reports to and from spreadsheets.

- Handles complex calculations such as conditional if-then statements.

- Provides a drag-and-drop utility in the reporting tree so users can see the financial effect of restructuring.

- Creates virtual roll-up structures for reporting at different levels - that is, by store, city, state, territory or country.

- $\quad$ Prepares and distributes presentation-quality reports using customized fonts, colors and other formatting options.

- $\quad$ Compares revenue and expense figures for different departments by creating side-by-side reports.

- $\quad$ Operates in a client-server environment. 


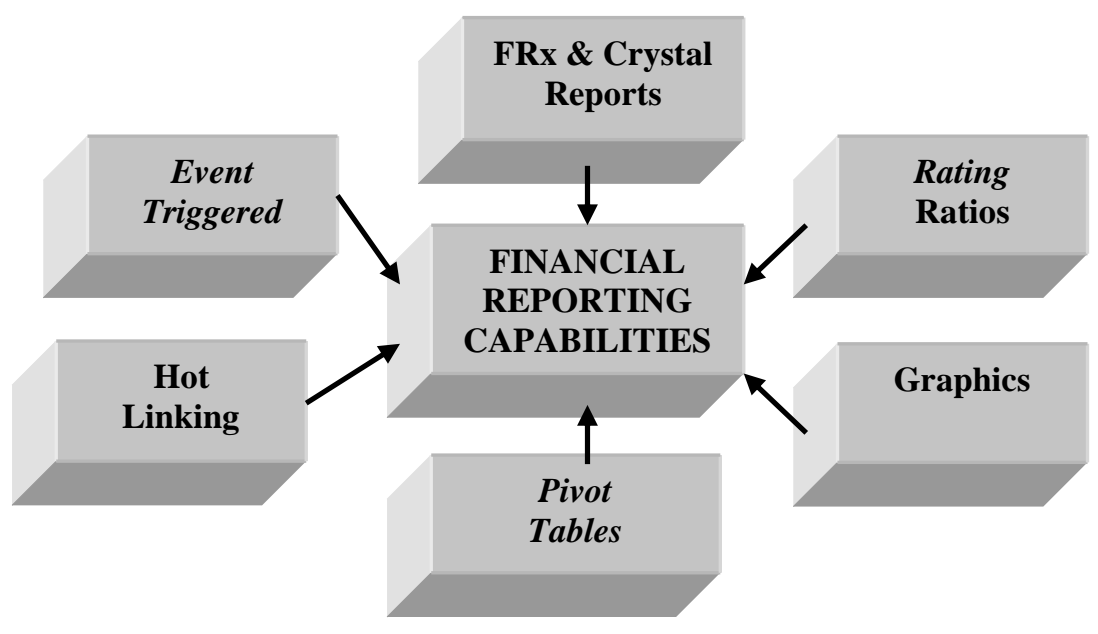

Figure 4: Financial Reporting Features

According to Collins (1999) FRx primarily offers superior reporting capabilities only from the general ledger module since it was not designed to extract data easily from other modules. However, Crystal Reports has the ability of extracting and reporting transactions from all modules. Both FRx and Crystal Reports are used by the top accounting software packages. Recently, FRx and Crystal Reports have been used by many organizations to resolve their inadequate financial reporting problems.

\section{Rating Ratios}

Another important attribute of financial reporting is the built-in ratio reporting. Unfortunately, most accounting software and third-party application developers either ignore this function or don't give it the considerable attention it deserves.

Collins (1999) mentioned that one of the few products that adequately addresses this need is Business Works for Windows - a product that serves the low-end market. Each of its modules contains a flash report function that summarizes key financial ratios and highlights key information. The general ledger flash report displays 20 key ratios for the following periods: current, year-to-date and prior-year. Also displayed are sales histories and balance sheet amounts for the past 24 months. The inventory flash report provides, among other things, inventory ratios, days in inventory, a reconciliation of the inventory account for the month, inventory and cost-of-goods-sold balances as well as highlights of the fastest selling and highest profit items. This is vital information that helps management detect problems in time to take corrective measures. In any company, it is important for management to receive a set of financial statements at least monthly, complete with financial ratio reports attached.

\section{Graphics}

A picture is indeed worth a thousand words, but it's probably worth several thousand numbers. One should check to be sure the accounting software package he/ she is considering could convert numbers into graphics. Several accounting packages can produce pie, line and area charts from the numerical data (Collins, 1999; Abu-Musa, 2004).

\section{Pivot Table}

One of the most powerful analytical tools is pivot tables. Pivot tables are an important tool used in spreadsheets that allows the user to take data and pivot, or turn, it in many different ways so the information can be viewed from different perspectives. For example, it can show the relationship between, say, sales in various cities and 
sales of individual products, and then, by pivoting the data, it can compare sales broken down by cities with those by individual outlets or by individual sales people (Collins, 1999).

\section{Hotlinking}

Another important financial report feature is the ability to hotlink accounting data directly to an Excel or Lotus 1-2-3 spreadsheets a feature first found in Platinum for Windows. Such a feature allows the user to export financial statements directly to Lotus or Excel as easily as sending the report to a printer (Collins, 1999).

\section{Event Triggered Reporting (Alarms)}

Many accounting software products have the ability to alert users to predefined financial conditions. With such a feature a chief financial officer (CFO) can create simple calculations that the accounting software continuously compares against a preset value. When that value is exceeded, an alert pops on the computer screen. For example, a CFO might create calculations to sound an alert if cash on hand falls below $\$ 100,000$, gross margin drops below $20 \%$ or the number of days in inventory exceeds 80 . In most cases, there is no limit to the number of triggers that can be established (Collins, 1999).

Accounting software could not only monitor custom events, but it also could alert managers by sending them e-mails. Its alarms automatically monitor amounts related to account balances, customers, vendors and employees. For accounting software packages that don't provide event-triggered alarms, a third-party solution often is available.

\section{Account Numbers Structure}

A quick and simple feature that should be investigated and considered in selecting the accounting software is the size and segmentation of the product's account number structure. One could eliminate an inadequate product by first checking this feature. Collins (1999) argued that there are many reasons why it's important to have a larger account number structure. Today's larger companies often have subsidiaries and divisions that must be identified in the accounting system by a fourth, fifth or sixth segments in the account number. In fact, most large not-for-profits organizations need at least four segments in their account number structures - for the account, sub-account, department and program. Many government agencies need at least four segments in their account number structures to identify the account, sub-account, department, and fund.

Again, Collins (1999) confirmed that the account number structure is an important feature which could knock any accounting software out of the running instantly. If that structure is inadequate -no matter how superior the product in every other way- the software should be rejected.

\section{Web Features And E-Commerce}

In recent years, many accounting software products have begun to add web features and e-commerce capabilities to their products. As the Internet continues to change the way organizations carry out business, these features will become increasingly more important. Therefore, organizations' managers should rethink and reinvest their expectations and requirements from the potential accounting software.

Recognizing this trend, many accounting software vendors have added features designed to accommodate the Internet. The new functions include the ability to:

- $\quad$ Publish Web catalogs directly from, and make links to, the software's inventory module. This means customers can see, among other things, real-time information on prices and quantities on hand.

- Retrieve orders directly from the Web site and import them automatically into the sales order module.

- $\quad$ Print all reports to a Web page format.

- $\quad$ Allow users to access reports and accounting data across the Internet using a password. 
- $\quad$ Let remote users securely enter accounting data and transactions via the Web.

- $\quad$ Track an order automatically via links to tracking pages of Federal Express or United Parcel Service.

- $\quad$ Allow users to e-mail reports to users or groups of users.

- $\quad$ Configure a system to automatically send e-mail reports and messages when triggered by predefined events (Collins, 1999).

\section{Foreign Currency}

Collins (1999) argued that the international marketplace has never been stronger, and the Internet is making that huge market more accessible to even the smallest enterprises. Companies with Web sites suddenly find prospects from halfway around the world can order their products as easily as a customer down the street. Businesses that have never dealt with any currency other than the U.S. dollar are finding they must contend with pounds and rubles and yen and euros, and for the first time they must consider the need for accounting software that supports foreign currency transactions and reporting.

Therefore, in evaluating multi-currency accounting software, one needs to look for several key features. Good multi-currency accounting software should let the end user generate consolidated reports in any currency and to translate financial reports into multiple currencies (Muller, 1994).

According to Collins (1999), only a handful of accounting packages process multiple currencies in compliance with FASB Statement no. 52, Foreign Currency Translation, Statements of Standard Accounting Practice 20 (the United Kingdom and Canadian authoritative pronouncement), International Accounting Standard 21, Accounting for the Effects of Changes in Foreign Exchange Rates (the IASC's authoritative pronouncement), or the European Community EC Directives 4 (Annual Account of Certain Types of Companies) and 7 (Council Directive on Consolidated Accounts). Accordingly, Collins recommended that if foreign currency features is one of the vital requirements of an organization, the following features should be considered in selecting accounting software:

- $\quad$ FASB 52-Compliant

- $\quad$ Foreign Currency Supported in General Ledger

- $\quad$ Foreign Currency Supported in Accounts Payable

- $\quad$ Foreign Currency Supported in Accounts Receivable

- $\quad$ Foreign Currency Supported in Inventory

- $\quad$ Euro-Compliant

- $\quad$ Supports Foreign Languages

Unfortunately, many accounting software packages are still "single currency" and don't provide "multicurrency" support at all. Such accounting software would not be ideal for foreign trade. "Multi-currency" is very important feature to be considered in selecting accounting software, especially for international organizations. The selected software should capabilities of doing foreign currency computations according to the floating daily exchange rate for each relevant foreign currency producing reports that show the effects of favorable and unfavorable exchange rate fluctuations.

Collins (1999) argued that foreign currency requirements became even more complicated as the euro became the official currency of the European Union (EU). Some EU companies already were adjusting for the euro. However, since the new euro coins and notes entered circulation, all EU businesses must use the euro as their local currency. Currently, 15 countries plan to participate in the conversion to the euro: Austria, Belgium, Britain, Denmark, Finland, France, Germany, Greece, Ireland, Italy, Luxembourg, the Netherlands, Portugal, Spain and Sweden. Therefore, if one plans to do business in Europe, his/her accounting software should be euro-compliant. 


\section{Databases Supported}

It is documented that most of today's accounting software could run the top multiple databases. Therefore, it is the end-users decision to select the appropriate database based on size and volume of their transactions. It could be a costly mistake to under-buy or over-buy a database. If the database is too weak, the accounting system will perform poorly costing an organization hundreds of hours of productivity. If the system is too robust, an organization may pay tens or even hundreds of thousands of dollars extra for the higher end database, higher implementation fees, and higher on-going consulting fees to maintain the system. Therefore, an organization should select the database that matches its unique needs. Selecting the appropriate database could not only can save lots of money but the accounting package can also run faster and better, even allowing it to be scaled up as the business grows (see: Collins, 1999).

\section{Product Modules}

It is argued that sometimes it could be difficult to determine exactly which modules are offered by a given accounting software package. Therefore, organizations should check the accounting models provided by a certain accounting software package and whether these models satisfy their requirements and expectations. However, many of the missing accounting modules might be available and provided by third party vendors.

The accounting models that might be provided by an accounting software package include: Activity-Based Management, Asset Management, Balanced Scorecard, Benefits Administration, Billing, Budgets, Cash Management, Deal Management, Demand Planning, eBusiness Backbone, Enterprise Performance Management, Enterprise Planning, Enterprise Warehouse, eProcurement, eStore, Expenses, FSA Administration, Funds Transfer Pricing, General Ledger, Human Resources, Inventory, Order Management, Order Promising, Payables, Payroll, Payroll Interface, Pension Administration, PeopleSoft Accounting and Control, PeopleSoft Advancement, PeopleSoft Customer Management for Utilities, PeopleSoft Enterprise Performance Management, PeopleSoft Financial Management for Education and Government, PeopleSoft Grant Management, PeopleSoft HRMS, PeopleSoft HRMS for Education and Government, PeopleSoft HRMS for Federal Government, PeopleSoft Materials Management, PeopleSoft Merchandise Management, PeopleSoft Procurement, PeopleSoft Product Development, PeopleSoft Production Management, PeopleSoft Profitability Management for Financial Services, PeopleSoft Project Management, PeopleSoft Sales and Logistics, PeopleSoft Service Revenue Management, PeopleSoft Student Administration, PeopleSoft Supply Chain Planning, PeopleSoft Treasury Management, Performance Measurement, Product Configurator, Projects, Purchasing, Receivables, Remote Order Entry, Risk Management, Risk Weighted Capital, Stock Administration, Time and Labor, Trimark Transcend for Insurance Policy Administration, Vantive Architecture and Technology, Vantive Contact Center, Vantive e-business, Vantive Enterprise, Vantive Field Service, Vantive Field Services, Vantive Help Desk, Vantive Sales, Vantive Support, Vantive Web Applications, Workbenches, Workforce Analytics, and others.

\section{Price For Eight Core Modules}

One of the important factors that might affect the choosing among packages is cost of acquiring the accounting software. Modern accounting packages are remarkably inexpensive to purchase, but deceptively costly to install and operate. The costs of training, vendor support, data conversion, and backups are almost guaranteed to dwarf the software's initial purchase price. The software decision could also affect future hardware purchases (Simkin, 1992).

However, in an attempt to compare apples to apples, one should compare the different vendors' retail prices for eight core modules of accounting software (general ledger, accounts receivable, accounts payable, payroll, inventory, order entry, job costing, and system manager). The price of the eight core modules would present a valid base for comparison. However, even with this approach there are still comparison problems; for example, some products include a report writer in the general ledger while others might charge extra. Still, these prices offer a reasonable basis for comparison. One may also want to check out the special pricing deals that come up from time to time (Collins, 1999; Hedtke, 2002; and Abu-Musa, 2004). 


\section{Security Feature Of Accounting Software}

Security of computerized systems is a broad concept, encompassing not only the consideration for privacy and keeping information secret (confidentiality), but also the issues of system integrity and availability. Therefore, the need to preserve the accuracy of information and the integrity of data transactions and to ensure the continued availability or continuity of services of the system should be also considered in preserving security. Conversely, threats to system security can threaten the integrity and accuracy as well as the availability of that system and its data (Harris and Sidwell, 1994, p. 548).

Davis (1996) stated that it is an accepted fact that new technology increases the security risks in accounting information systems. McIntyre (1991) confirmed that security threats to an organization's computerized accounting systems are now too well documented to be ignored. Yet many organizations still fail to take computer security seriously enough. The "it can't happen here" attitude is still alive in many organizations.

In the USA, The American Department of Defense has issued the "Orange Book" series. This contains 17 documents that provide a comprehensive set of guidelines both for people introducing computer security measures and for companies developing secure computer systems and products. In addition, The Advisory Committee for the Coordination of Information Systems (ACCIS) (1992) has issued "Information System Security Guidelines for the United Nation Organizations". This book aims to provide assistance to managers in the United Nations organization who are looking for adequate and cost effective security for their information systems. Moreover, The Trusted Computer Security Evaluation Criteria (TCSEC), and The Information Technology Security Evaluation Criteria (ITSEC) provide the criteria that should be considered in evaluating the security aspects of accounting software packages (Abu-Musa, 2001; Solms, 1996)

In the UK, "The Code of Practice for Information Security Management" was published in late 1993. Later, this code of practice was transformed into a standard (The British Standard BS 7799). The main objective of both initiatives is to provide a common basis for companies to develop, implement and measure effective security management. In addition, there is the Data Protection Act, issued in 1987 and revised in 1998.

In Germany, The German Accounting Information Security Agency (Zentralstelle fur sicherheit in der informationstechnik) published in July 1989 its "Criteria for the Evaluation of Trustworthiness of information Technology Systems" (for more details, see Roux, 1991, P. 61). Therefore, security issues should be considered and investigated in order to select a reliable, secured accounting software.

\section{Other Accounting Software Features}

There are many other important features and attributes that should be considered when selecting among alternative accounting software packages such as: the programming language used to develop the selected accounting software products, The number of the customers using the accounting software that might represent an indicator of the popularity of the accounting software in the market, the existence of useful links to the third-party applications on web pages, availability of application hosting, and the size and reliability of the vender's company (see figure 2).

\section{3. INFORMATION TECHNOLOGY ENVIRONMENT AND INFRASTRUCTURE}

Many organizations often seek to find an accounting software solution that would run on their current computer equipment. The problem with such approach is that it is backward, it puts the cart in front of the horse. The best way to proceed is to find the accounting software that best meets an organization's needs, and only then find the best hardware to run it. If an organization's current hardware could be utilized, that would be great. If an organization's current hardware is inadequate, then it should purchase a new hardware. Purchasing new hardware equipment is by far the least expensive component when it comes to implementing a new accounting system. Chances would be that if an organization needs to replace its accounting system, then it also time to replace your hardware anyway (Collins, 1999, Abu-Musa 2004). Again, Soukup (2000) confirmed that new software will dictate hardware 
equipment. If users' computers are old, they may need to reinvest. Network upgrades may be necessary, based on the system compatibility requirements of the new software.

\section{4. VENDOR RELIABILITY}

Availability of reliable local vendors is very important. In cases that the vendor does not have local staff in place, it should have strategic relationship with third party firms to provide training and consulting services, as well as technical assistance. Regardless of the suitability of the accounting software, users still need to rely on continued support from the vendor. Accordingly, in selecting accounting software one should assure that the vendor is reliable, has the resources to meet an organization's requirements and will be available when needed.

West and Shields (1998) mentioned that the vendor of accounting software package would become a strategic partner of the organization for many years, so the selection process should investigate the ability of the vendor to support the future needs of the organization and, in effect, drive the use of future technologies to support the business processes. Collins (1999) confirmed the meaning that many of first-time accounting software users are tending to disregard vendor reliability by focusing primarily on the product's quality, price or both. However, selecting a product and then entrusting it with all the organization's financial data is not unlike the goals of a marriage: one wants a fruitful, long-term relationship. Once the product is installed, the customer depends on the accounting vendor to supply updates for payroll taxes, sales taxes and even depreciation rates. The customer also must rely on the vendor to fix the inevitable bugs, provide support and continually enhance the product to run on the latest platforms and operating systems. The continued success of the accounting software vendor has a direct bearing on the customer's continued success with the accounting software.

\section{E. DETERMINATES OF SELECTING APPROPRIATE ACCOUNTING SOFTWARE: A PROPOSED MODEL}

Based on the theoretical analysis in first part of this paper, it could be argued that selecting the most appropriate accounting software for an organization would be a function in the following variables: the end users' current and future needs, business type, business size, accounting software features, information technology environment and infrastructure, and vender reliability. However, the real shape of the function could not be determined without investigating it using real empirical data., and such data is not available now due to the paucity of studies in that area. Although we expect a positive relationship between selecting the appropriate accounting software for an organization and the above variables, further, interrelationships and correlations among those variables could be also found. Therefore, it would be convenient for research purposes to assume the existence of a linear relationship between selecting appropriate accounting software and the suggested above determinates. Such assumption is used in many of the previous studies that facing the same problem. The general equation of the proposed model could be formulated as follows:

$$
\boldsymbol{Y}=\frac{1}{n} \sum_{i=1}^{n} \sum_{k=1}^{m} \boldsymbol{D}_{i, k} \quad \text { (The general equation of the proposed model) }
$$

Where:

$\mathrm{Y}=$ Average number of points assigned for an accounting software;

$\mathrm{i}=$ Index of the evaluation committee members from 1 to $\mathrm{n}$;

$\mathrm{n}=$ Total number of evaluation committee members;

$\mathrm{k}=$ Index of selection determinants of accounting software from 1 to $\mathrm{m}$;

$\mathrm{m}=$ Total number of selection determinates; and

$\mathrm{D}=$ Total number of points assigned to the determinants of an accounting software. 
However, the previous general equation of the proposed model could be rewritten to present the individual determinants of selecting accounting software " $\mathrm{D}$ " as follows:

$$
Y=\frac{1}{n} \sum_{i=1}^{n}(\mathrm{CN}+\mathrm{FN}+\mathrm{BS}+\mathrm{BT}+\mathrm{ASF}+\mathrm{ITE}+\mathrm{VR})
$$

Where:

$\mathrm{Y}=$ Average number of points assigned for an accounting software;

$\mathrm{i}=$ Index of the evaluation committee members from 1 to $\mathrm{n}$;

$\mathrm{n}=$ Total number of evaluation committee members;

$\mathrm{CN}=$ Total number of points assigned to the firm's current needs;

$\mathrm{FN}=$ Total number of points assigned to the firm's future needs;

$\mathrm{BS}=$ Total number of points assigned to the business size;

$\mathrm{BT}=$ Total number of points assigned to the business type;

$\mathrm{ASF}=$ Total number of points assigned to the features of accounting software;

ITE $=$ Total number of points assigned to the IT environment and infrastructure; and

$\mathrm{VR}=$ Total number of points assigned to the vender reliability.

The main features and attributes of the selected accounting software should match an organization's current requirements and satisfy its future needs and expectations of information and financial and non-financial reports. It should also comply with the nature and the volume of an organization's transactions. Further, the selected accounting software should be competitive and compatible with the existing information systems and integrated with other programs in place. The main features and attributes that should be considered in selecting appropriate accounting software packages for an organization are: customization capabilities, financial reporting, account numbers structure, web features and e-business, foreign currency, databases supported, product modules, price for eight core modules, reseller programs, number of customers, links to third party, programming language, hosting, and security issues as it is shown in the following equation:

$$
\mathrm{ASF}=\sum_{i=1}^{n}(\mathrm{CC}+\mathrm{FR}+\mathrm{ANS}+\mathrm{WEBF}+\mathrm{EBF}+\mathrm{FC}+\mathrm{DS}+\mathrm{PM}+\mathrm{PECM}+\mathrm{SF}+R P+N C+L T P+P L
$$

Where:

ASF $=$ Total number of points assigned for the main features of an accounting software;

$\mathrm{i}=$ Index of the evaluation committee members from 1 to $\mathrm{n}$;

$\mathrm{n}=$ Total number of evaluation committee members;

$\mathrm{CC}=$ Total number of points assigned to customization capabilities;

$\mathrm{FR}=$ Total number of points assigned to financial reporting attributes;

ANS = Total number of points assigned to account numbers structure attribute;

$\mathrm{WEBF}=$ Total number of points assigned to web features;

$\mathrm{EBF}=$ Total number of points assigned to e-business attribute;

$\mathrm{FC}=$ Total number of points assigned to foreign currency attribute;

DS = Total number of points assigned to databases supported attribute;

$\mathrm{PM}=$ Total number of points assigned to product modules attribute;

PECM = Total number of points assigned to price for eight core modules attribute;

$\mathrm{SF}=$ Total number of points assigned to security features;

$\mathrm{RP}=$ Total number of points assigned to reseller programs attribute;

$\mathrm{NC}=$ Total number of points assigned to number of customers attribute;

LTP $=$ Total number of points assigned to links to third party attribute;

$\mathrm{PL}=$ Total number of points assigned to programming language attribute; and

$\mathrm{HA}=$ Total number of points assigned to hosting attribute. 
The customization feature of accounting software includes many sub-features and levels of customization such as: financial statement-level customization, forms-level customization, screen-level customization, blank user definable fields, default settings, database-level customization, third party integration customization, and help-level customization. The main customization capabilities that would affect selecting an appropriate accounting software package for an organization are reflected in the following equation:

$$
\mathrm{CC}=\sum_{i=1}^{n}(\mathrm{FSLC}+\mathrm{FLC}+\mathrm{SLC}+\mathrm{BUDF}+\mathrm{DS}+\mathrm{DLC}+\mathrm{TPIC}+\mathrm{HLC})
$$

Where:

$\mathrm{CC}=$ Total number of points assigned to customization capabilities of an accounting software;

$\mathrm{i}=$ Index of the evaluation committee members from 1 to $\mathrm{n}$;

$\mathrm{n}=$ Total number of evaluation committee members;

FSLC $=$ Total number of points assigned to financial statement-level customization;

FLC $=$ Total number of points assigned to forms-level customization;

SLC $=$ Total number of points assigned to screen-level customization;

BUDF $=$ Total number of points assigned to blank user definable fields;

DS = Total number of points assigned to default settings attribute;

DLC $=$ Total number of points assigned to database-level customization;

TPIC $=$ Total number of points assigned to third party integration customization; and

HLC $=$ Total number of points assigned to help-level customization.

The most important aspects of financial reporting attribute are: the built-in FRx and Crystal reports; rating ratios, graphics, pivot tables, hot-linking, and event triggered reporting. The main elements of the financial reporting characteristics and attributes are presented in the following equation:

$$
\mathrm{FR}=\sum_{i=1}^{n}(\mathrm{FR} x \mathrm{CR}+\mathrm{RR}+\mathrm{G}+\mathrm{PT}+\mathrm{HL}+\mathrm{ETR})
$$

Where:

$\mathrm{FR}=$ Total number of points assigned to financial reporting features of an accounting software;

$\mathrm{i}=$ Index of the evaluation committee members from 1 to $\mathrm{n}$;

$\mathrm{n}=$ Total number of evaluation committee members;

FRxCR $=$ Total number of points assigned to built-in FRx and Crystal reports;

$\mathrm{RR}=$ Total number of points assigned to rating ratios;

$\mathrm{G}=$ Total number of points assigned to graphics;

$\mathrm{PT}=$ Total number of points assigned to pivot tables;

$\mathrm{HL}=$ Total number of points assigned to hot-linking; and

ETR $=$ Total number of points assigned to event triggered reporting.

The proposed model of the determinants of selecting accounting software is quite flexible. The maximum points assigned for each determinant in the proposed model is not rigid and could be differed from one organization to another according to the materiality and significant importance of each determinant to that organization. The proposed model could be also used by different types of organizations in different size. The proposed model is expected to help organizations in selecting the most appropriate accounting software which suits their requirements and future expectations. The empirical procedures of implanting the proposed model are presented in the next section. 


\section{F. THE PROCEDURES FOR IMPLEMENTING THE PROPOSED MODEL}

The practical procedures for implementing the proposed model for selecting the appropriate accounting software for an organization could be determined in the following main steps:

- A committee should be formulated from all department chairmen in an organization to study and specify the current and future needs for the accounting software regarding the required information and financial and non-financial reports. The heads of the accounting, internal audit, and computing departments should be represented in that committee. The committee should also study the effect of the nature and volume of business transactions in an organization on its requirements from accounting software. A market study should be carried out to collect information of the competing available accounting software and to explore the end users, and other related parties from information and financial reports in the light of the organization's strategy and future plans.

- $\quad$ The committee should have a list of accounting software packages available in the market that are expected to satisfy their organization's current and future needs. The committee should study the main features and attributes of accounting software taking into consideration the determinates of selecting accounting software (Appendix 1).

- $\quad$ The committee should exclude the accounting software which does not have some of the main and important features and attributes. Towards this end, the committee would prepare a short list of the strongly recommended accounting software. The committee should consider the status of availability of information technology and infrastructure in the organization, and check whether the proposed accounting software is compatible with the available Pc's and integrated with other systems. Colleting information regarding the vender reliability, the cost of acquisition, operating and maintenance cost of the accounting software, and other important factors are considered very important primarily data for implementing the proposed model.

- $\quad$ The selecting committee should specify (estimate) the maximum points that should be assigned to each of the selecting determinants in the proposed model according to its relative importance or materiality for an organization by filling the required data of the respective column in the suggested evaluation statement of accounting software (Appendix 1).

- $\quad$ The average number of points for each determinant and its inherent components should be calculated by dividing the total number of points assigned for that determinant by all committee members divided by the total number of the committee members.

- $\quad$ The maximum points assigned for the selecting determinants in the proposed evaluation statement would then be used as a benchmark for evaluating the competitive accounting software.

- $\quad$ Each committee member should study and evaluate the individual suggested accounting software and assign a number of points to each determinant or attribute and its components using the proposed evaluation sheet in Appendix 1, taking into consideration the maximum points assigned for each determent and its individual components. A separate statement should be completed for each individual proposed accounting software by each member of the evaluation committee.

- If great variations appear among the committee members regarding their evaluation of the materiality of the determinants and, accordingly, the maximum points assigned for each determinant, Delphi technique should be implemented in that case to reach a reasonable and acceptable level of consistency in their evaluation regarding the relative importance of each determinant and its components.

- $\quad$ External consultants and professionals could participate - if it is necessary - in the selection process and to give advice if such experttees needed for the selection process is not internally available in the organizations.

- $\quad$ Total number of assigned points for each accounting software by all evaluation committee members should be calculated, then the average points assigned for each accounting software should be calculated (total number of points assigned for a specific accounting software by all the committee members divided by the total number of the evaluation committee members)

- $\quad$ The committee should select the accounting software that gains the highest average of points that have been calculated in the previous step. It is expected that the selected accounting software in that case will achieve the best matching (satisfaction level) of the organization's current and future needs for 
information, and financial and non-financial reports. It would be the most convenient and suitable for an organization's strategies and objectives and comply with its nature and volume of transactions. Accordingly, it is expected, in general, to achieve the best matching and satisfaction according to the criteria and determinates used in proposed model.

- Again, in a case where significant variations were found in the actual evaluation of the accounting software from the committee members, Delphi technique could be implemented in the same way as mentioned above to reduce the variance and to reach an acceptable level of consistency in the committee evaluation in order to select the most appropriate accounting software for an organization.

\section{G. LIMITATION OF THE PROPOSED MODEL}

The suggested model would be beneficial in helping an organization in selecting the most appropriate accounting software. However, the following limitations should be considered in implementing the proposed model:

- $\quad$ The proposed model is mainly designed to help new established organizations that intend to acquire accounting software for the first time, and those organizations transferring from manual to computerized accounting systems in selecting the most appropriate accounting software. Regarding organizations which already have accounting software in place that does not satisfy their current and future needs for information and financial and non-financial reports, or does not comply with its objectives and strategies, the proposed model would help only in cases that such organizations decided to terminate their existing accounting software and to replace it entirely with a new one. The proposed model does not consider the alternative of repairing or upgrading the existing accounting software to be reused by such organizations.

- $\quad$ The maximum number of points assigned to each determinant of selecting accounting software and its sub-features in the proposed evaluating statement (Appendix 1) have been calculated by using Delphi technique. Delphi technique has been carried out on a selected sample which included three faculty members working in one of the most recognized universities in Saudi Arabia, two certified accountants from one the biggest Saudi accounting firms (partner of the Big Five), a head of internal audit department, and a head of computer department in one of the well known Saudi oil and gas companies. Therefore, the maximum number of points assigned to each determinant in the proposed evaluation statement (Appendix 1) represents the opinions of both academics and professionals regarding the materiality or the significant importance of selection determinants in the proposed model. Those proposed numbers should be used with due care as guidelines in implementing the proposed model. Therefore, the maximum points assigned for each determinant in the proposed statements could not be generalized or used as standards for all types of organizations, since it is based on relatively small size and heterogeneous sample. Moreover, the materiality of each determinant could be differed from one organization to another according to it size, type, current and future needs, IT environments and infrastructure, business strategy and future plans, and other factors as it is discussed in this paper.

- $\quad$ The current research does not aim to evaluate accounting software packages in the market for commercial proposes in order to decide which accounting software is the "best". The author believes that there is no what is called "best" accounting software. The "best" accounting software for one aromatization may not be the "best" for another. Accordingly, it could be argued that there is no single accounting software that would suit and satisfy everyone's needs, but there are probably several accounting software packages that could suit an organization's specific requirements.

\section{H. CONCLUSION}

The steady decline in the price of the information technology and the increasing availability of "off the shelf" accounting software have led many organizations of different sizes to automate all or part of their accounting functions. Therefore, selecting the most appropriate accounting software package that would satisfy an organization's current and future needs has become an important issue. The paper introduced an integrated framework of the main factors that should be considered in the selection process among the competitive accounting software packages. 
The paper also introduced a proposed mathematical model of the determinants of selecting accounting software for an organization, and presented the empirical steps and procedures for implementing it. The proposed model would be beneficial for new organizations purchasing accounting software for the first time, and organizations transferring from manual to computerized accounting systems. The proposed model is quite flexible since the maximum points assigned to each determinant and its components are not rigid, and could be differed from one organization to another according to the materiality and significant importance of each determinant to that organization.

The proposed model could be also used different size organizations, and it is expected to help organizations in selecting the most appropriate accounting software that would match their current requirements and future expectations for information and financial and non-financial reports. It is recommended to test the proposed model empirically using real data to investigate the validity and reliability of it in rationalizing the selection process among competitive accounting software in practice.

\section{REFERENCES}

1. Abu-Musa, Ahmad A. (2001). Evaluating the Security of Computerized Accounting Information Systems: An Empirical Study on Egyptian Banking Industry, Ph.D. Thesis, Aberdeen University, Scotland, UK.

2. Abu-Musa, Ahmad A. (2004). The Criteria For Selecting Accounting Software: A Theoretical Framework, Proceeding of The $2^{\text {nd }}$ Conference on Administration Sciences: Meeting The Challenges Of The

Globalization Age, King Fahd University of Petroleum and Minerals, Saudi Arabia, 19-21 April.

3. Advisory Committee for the Co-ordination of Information Systems (ACCIS). (1992). Information System Security Guidelines for the United Nations Organizations, United Nations, New York.

4. Basile, Anthony; Papa, Louis J., and Johnston, Randy. (2002). Leading high-end accounting software, The CPA Journal, New York, Volume 72, Issue 5, May, pp. 26-33.

5. Collins, J. Carlton. (1999). How to select the right accounting software, Journal of Accountancy, New York, Volume 188, Issue 2, August, pp. 61-69.

6. Collins, J. Carlton. Customizing Accounting Software, online at http://www.AccountingSoftware

7. advisor.com/topics/customization.htm.

8. Fisher, Dorothy M. and Fisher, Steven A. (2001). For Rent: Are you considering an ASP for your accounting functions?, The National Public Accountant, Washington, Volume 46, Issue 6, August, pp. 16-18.

9. Davis, Charles E. (1996). Perceived Security Threats to Today's Accounting Information Systems: A Survey of CISAs, IS Audit and Control Journal, Volume 3, pp. 38-41.

10. Davis, Charles E. (1997). An Assessment of Accounting Information Security, The CPA Journal, New York Volume 67, Issue 3, pp. 28.

11. Deshmukh, Ashutosh and Romine, Jeffrey. (2002). Accounting software and e-business, The CPA Journal, New York, November, Volume 72, Issue 11, pp 52-53.

12. Gurton, Annie. Spoiled for choice, Accountancy, London, Volume 127, Issue 1289, January 2001, pp. 64-65.

13. Harris, Duncan and Sidwell, David. (1994). Distributed Database Security, Computers and Security, Volume 17, Issue 3, pp. 547-557.

14. Henry, Laurie. (1997). A Study of the Nature and Security of Accounting Information Systems: The Case of Hampton Roads, Virginia, The Mid-Atlantic Journal of Business, Volume 33, Issue 63, pp. 171-189.

15. Hedtke, John. (2002). Low Cost Accounting, Accounting Technology, Boston, December, pp. 33-37.

16. International Federation of Accountants (IFAC), The Information Technology Committee, (1998), International Information Technology Guidelines: Managing Security of Information, January, New York.

17. Jones, Roberta Ann. (2002). Spotlight on midlevel ERP software, Journal of Accountancy, New York, Volume 193, Issue 5, May, pp. 24-47.

18. Mattingly, Tim. (2001). How to select accounting software, The CPA Journal, New York, Volume 71, Issue 11, pp. 48-52.

19. McIntyre, Andy. (1991). Security and The Mainframe Computer, Computer Security Guide, pp. 40-43.

20. Morey, Scott. (1999). Software 99, Journal of Property Management, Chicago, Volume 64, Issue 4, July/August, pp. 80-92. 
21. Muller, Nathan J. (1994). The Corporate Exchange Rate Mechanism, The Journal of European Business, New York, March/April, pp. 14-19.

22. OECD (Organization for Economic Co-operation and Development). (1992). Guidelines for the Security of Information Systems, The Council of the OECD, 26 November.

23. Sampson, William. (2003). Exploring Accounting Software, CabintMaker, Chicago, February, Volume 17, Issue 2, pp. 32-35.

24. Simkin, Mark G. (1992). Decision support tools for choosing accounting software, The CPA Journal, online November.

25. Solms, Rossouw Von. (1996). Information Security Management: The Second Generation, Computer and Security, UK, pp. 281-288.

26. Soukup, Carol. (2000). Evaluating an Accounting Software Change, The Wisconsin CPA, May.

27. Tate, John. (1999). How to select new business software, Management Accounting, London, April, Volume 77, Issue.4; pp. 52-55.

28. Tavakolian, Hamid. (1995). PC-based Financial Software: Emerging Options, Industrial Management and Data Systems, Wembley, Volume 95, Issue 10, pp. 19-24.

29. Roux, Yves. (1991). Technical Criteria for Security Evaluation of IT Products, Computer Security Guide, pp. 59-62.

30. West, Owen D., III and Zoladz, Christopher. (1993). Microcomputer Security: Is Your Organization at Risk?, EDP Auditor Journal, Volume 4, pp. 44-49.

31. West, Robert and Shields, Murrell. (1998). Strategic Software Selection, Management Accounting, Montvale, August, pp. 3-7. 


\section{(APPENDIX 1)}

The Determinates of Selecting Accounting Software

Name of Evaluation Member:

Name of the Accounting Software:

1. The Main Determinates Of Selecting Accounting Software

\begin{tabular}{|l|c|c|}
\hline \multicolumn{1}{|c|}{ The Determinates of Selecting Accounting Software } & $\begin{array}{c}\text { Maximum } \\
\text { points }\end{array}$ & $\begin{array}{c}\text { Points } \\
\text { Obtained }\end{array}$ \\
\hline 1. Number of points assigned to firm's current needs & 250 & \\
\hline 2. Number of points assigned to firm's future needs & 250 & \\
\hline 3. Number of points assigned to business size & 100 & \\
\hline 4. Number of points assigned to business type & 100 & \\
\hline 5. Number of points assigned to accounting software features & 550 & \\
\hline 6. Number of points assigned to IT environment and infrastructure & 50 & \\
\hline 7. Number of points assigned to vender reliability & 50 & \\
\hline 8. Other Total Number of Points & 50 & \\
\hline
\end{tabular}

2. The Main Features And Attributes Of Accounting Software

\begin{tabular}{|l|c|c|}
\hline \multicolumn{1}{|c|}{ The Features and Attributes of Accounting Software } & $\begin{array}{c}\text { Maximum } \\
\text { Points }\end{array}$ & $\begin{array}{c}\text { Points } \\
\text { Obtained }\end{array}$ \\
\hline 1. Number of points assigned to customization capabilities attributes & 120 & \\
\hline 2. Number of points assigned to financial reporting attributes & 90 & \\
\hline 3. Number of points assigned to account numbers structure attribute & 30 & \\
\hline 4. Number of points assigned to web features attribute & 30 & \\
\hline 5. Number of points assigned to E-business attribute & 30 & \\
\hline 6. Number of points assigned to foreign currency attribute & 30 & \\
\hline 7. Number of points assigned to databases supported attribute & 30 & \\
\hline 8. Number of points assigned to product modules attributes & 30 & \\
\hline 9. Number of points assigned to price for eight core modules attribute & 30 & \\
\hline 10. Number of points assigned to security issues attribute & 20 & \\
\hline 11. Number of points assigned to programming language attribute & 20 & \\
\hline 12. Number of points assigned to reseller programs attributes & 20 & \\
\hline 13. Number of points assigned to number of customers attribute & 20 & \\
\hline 14. Number of points assigned to links to third party attribute & 20 & \\
\hline 15. Number of points assigned to hosting attribute & $\mathbf{5 5 0}$ & \\
\hline Total Number of Points & & \\
\hline
\end{tabular}

\section{Customization Capabilities Of Accounting Software}

\begin{tabular}{|l|c|c|}
\hline \multicolumn{1}{|c|}{ Customization Capabilities of Accounting Software } & $\begin{array}{c}\text { Maximum } \\
\text { points }\end{array}$ & $\begin{array}{c}\text { Points } \\
\text { Obtained }\end{array}$ \\
\hline 1. Number of points assigned to financial statement-level customization & 15 & \\
\hline 2. Number of points assigned to forms-level customization & 15 & \\
\hline 3. Number of points assigned to screen-level customization & 15 & \\
\hline 4. Number of points assigned to blank user definable fields & 15 & \\
\hline 5. Number of points assigned to default settings & 15 & \\
\hline 6. Number of points assigned to database-level customization & 15 & \\
\hline 7. Number of points assigned to third party integration customization & 15 & \\
\hline 8. Number of points assigned to help-level customization. & 15 & \\
\hline Total Number of Points & $\mathbf{1 2 0}$ & \\
\hline
\end{tabular}


4. Financial Reporting Features Of Accounting Software

\begin{tabular}{|l|c|c|}
\hline \multicolumn{1}{|c|}{ Customization Capabilities of Accounting Software } & $\begin{array}{c}\text { Maximum } \\
\text { points }\end{array}$ & $\begin{array}{c}\text { Points } \\
\text { Obtained }\end{array}$ \\
\hline 1. Number of points assigned to built-in FRx and Crystal reports & 15 & \\
\hline 2. Number of points assigned to rating ratios & 15 & \\
\hline 3. Number of points assigned to graphics & 15 & \\
\hline 4. Number of points assigned to pivot tables & 15 & \\
\hline 5. Number of points assigned to hot-linking & 15 & \\
\hline 6. Number of points assigned to event triggered reporting & 15 & \\
\hline Total Number of Points & $\mathbf{9 0}$ & \\
\hline
\end{tabular}

NOTES 
NOTES 